\title{
Multidirectional Forging Simulation Research on a Tee Joint Valve
}

\author{
Jin-Hua HU ${ }^{1, a}$, Shi-Peng SHI ${ }^{2}$, Yun-Lai REN ${ }^{3}$, Zhong-Hai $\mathrm{YU}^{4}$ \\ ${ }^{1,3,4}$ Shanghai Dianji University, China \\ ${ }^{2}$ Yanshan University, China \\ acae007@126.com
}

Keywords: Forging, Simulation, Finite element analysis, Tee Joint valve.

\begin{abstract}
A numerical tee joint valve model was set up in this paper. The numerical forming simulation was implemented. The load of the upper punch was predicted. The final temperature field shows that varying temperatures are within the feasible forging temperature region. The results from the numerical simulation were verified through the practical experiment.
\end{abstract}

\section{Introduction}

The multidirectional forging technology can markedly improve the performance of the forging and increase the forming efficiency.

In China, the research on the multidirectional forging technology commenced in the 1970s. Important progress has been made since 1980s. In 2000, Huang [1] proposed some design main points with regard to the multidirectional forging moulds. In 2008, Bai \& Zhang [2] applied MSC/Superform to simulate the multidirectional forging process of a square tee joint and revealed the metal flow regulation during the multidirectional forging process. Li \& Xue [3] carried out thermal-mechanical coupling finite element analysis for the multidirectional forging process and proposed reference for formulating the forging process scheme. In 2011, Shi, Ding \& Zhu [4] studied and formulated the multidirectional forging process for the tension rod joint. The previous disadvantages of the open-die forging were avoided efficiently. In 2012, Yu, Zhang etc. [5] developed a curved parting concave die and successfully resolved the flash problem during the multidirectional forging process.

In summary, the previous scholars provided methods for the research on the multidirectional forging technology.

This paper focused on the multidirectional forging process of material P91. The research contents mainly include optimization of the forming technology and evolution of the forgings' microstructure during the forming process. The numerical simulation work was introduced in this paper only.

\section{Numerical Simulation on a Tee Joint Valve}

\section{Model Setup}

The 3D model of the forging, which was shown in Fig. 1, was set up applying the software UGNX. The quarter multidirectional forging moulds were designed, as shown in Fig.2. The material properties were computed with the software JmatPro. The billet is a cylinder part, with the diameter $210 \mathrm{~mm}$, the height $410 \mathrm{~mm}$. The initial temperature of the billet is $1150{ }^{\circ} \mathrm{C}$, the moulds $250{ }^{\circ} \mathrm{C}$. The environment temperature is $25{ }^{\circ} \mathrm{C}$. The lubrication material is colloidal graphite in water. The moving velocities of the upper punch and the side punch are $75 \mathrm{~mm} / \mathrm{s}$. The displacement of the upper punch and the side punch are $430 \mathrm{~mm}$ and $150 \mathrm{~mm}$ respectively.

\section{Temperature Field Analysis}

During the thermal plasticity forming process, the temperature has marked influence. It is very helpful to grasp the distribution of the temperature during the multidirectional forging process.

Fig. 3 shows the distribution of the temperature at several typical forming stages. During the forging process, the plastic deformation of the billet resulted in plastic work. Most of the plastic work 
converted to heat, which was mainly absorbed by the billet itself. Therefore, the temperature of the billet can increase during the multidirectional forging process. Fig. $4 \mathrm{a}$ shows that the temperature at the billet center increases markedly due to the action of the upper punch. The maximum temperature of the billet increases from $1150{ }^{\circ} \mathrm{C}$ to $1186{ }^{\circ} \mathrm{C}$. Fig. $4 \mathrm{~b}$ shows that the temperatures vary from $837{ }^{\circ} \mathrm{C}$ to $1191{ }^{\circ} \mathrm{C}$. The region where the temperature is above the initial temperature enlarged. After this time point, the side punch begins to move. Therefore, the upper punch and the side punch finish the forging process at the same time. The reason of moving the side punch at this time point, i.e. the displacement of the upper punch is $280 \mathrm{~mm}$, is that the fold defection may be avoided effectively based on the simulation. Fig. $4 \mathrm{c}$ shows that the maximum temperature increases to $1207^{\circ} \mathrm{C}$ due to the combined action of the two punches. Fig. $4 \mathrm{~d}$ shows that the maximum temperature at the central region of the forging is relatively high, while the surface region is as low as $792{ }^{\circ} \mathrm{C}$. It can be seen from the temperature filed that the varying temperatures are within the feasible forging temperature region.

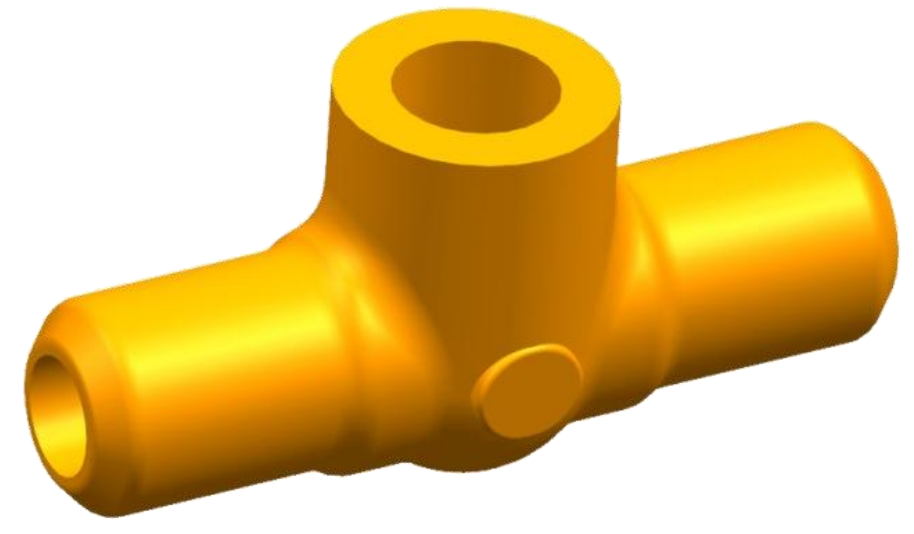

Fig. 1 The tee joint forging

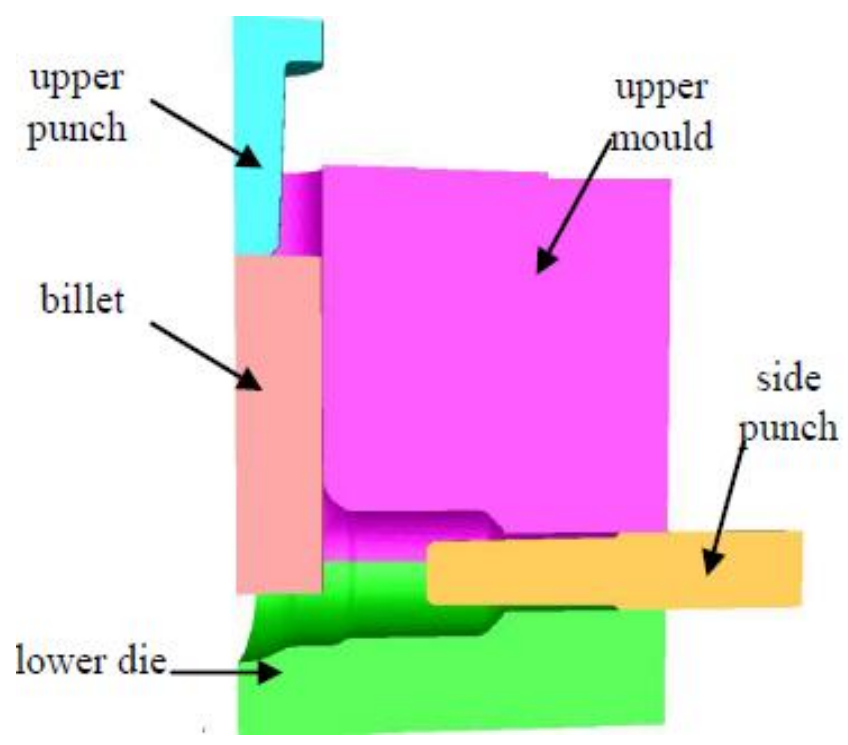

Fig. 2 The moulds

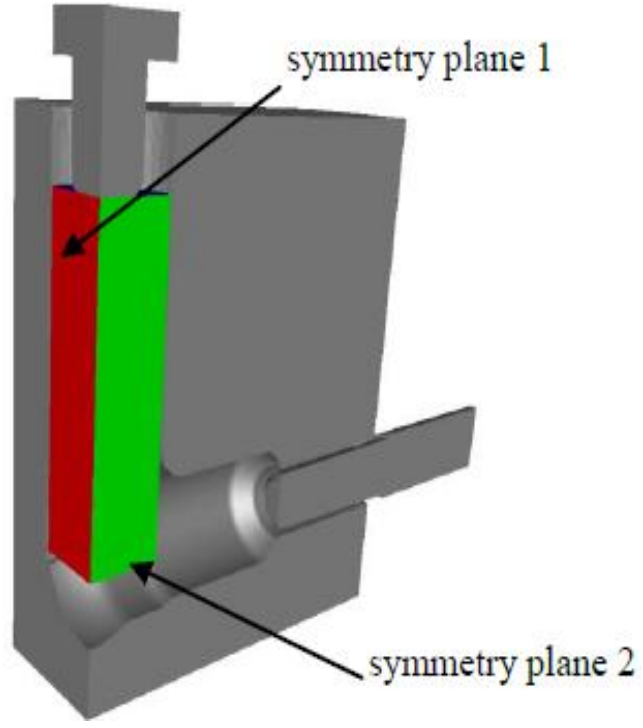

Fig. 3 Definition of the symmetric planes

\section{Experimental Verification}

Fig. 5 shows the forgings from the simulation and the practical production respectively. It can be seen that the shapes are almost the same. Fig. 6 shows the stroke vs. load curves from the simulation and the experiment. The difference between the computed load value and the practical load value is within $10 \%$. 

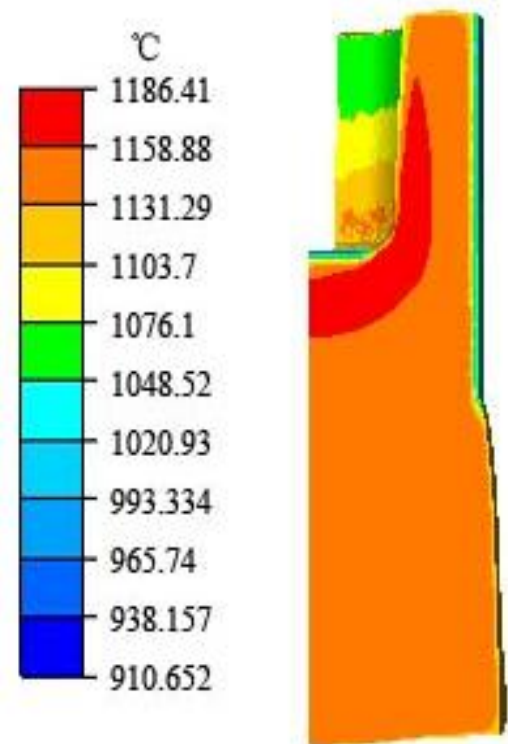

a) Temperature field at displacement $=160 \mathrm{~mm}$
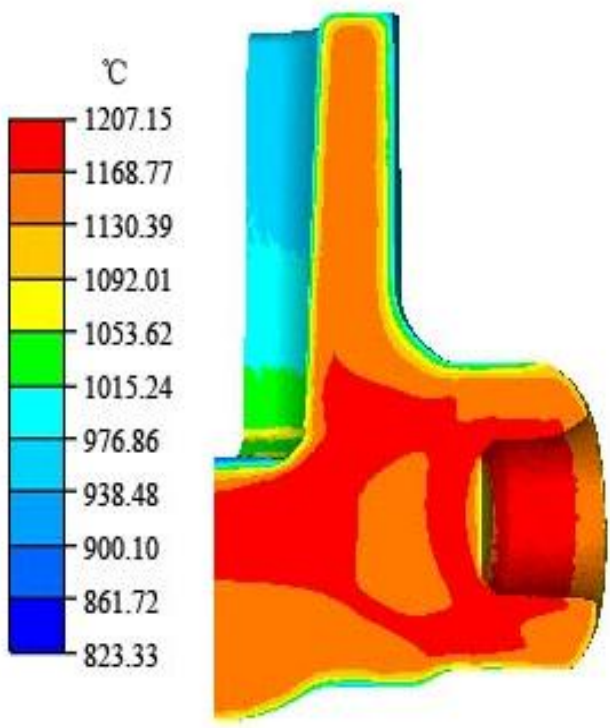

c) Temperature field at displacement $=360 \mathrm{~mm}$
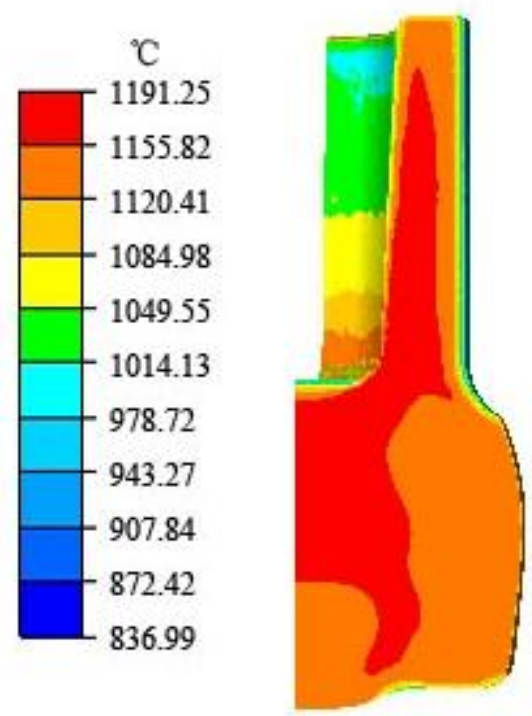

b) Temperature field at displacement $=280$ $\mathrm{mm}$

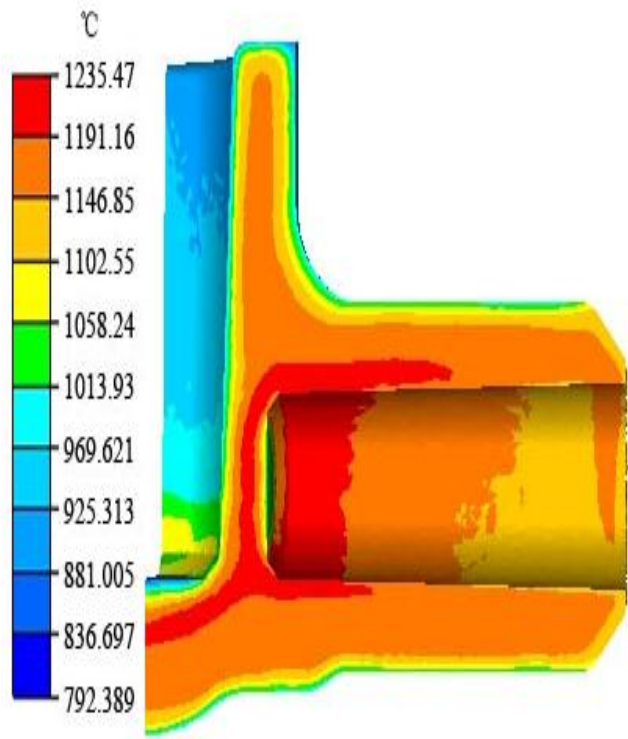

d) Temperature field at displacement $=430$ $\mathrm{mm}$

Fig. 4 Evolution of the temperatures during the forging process

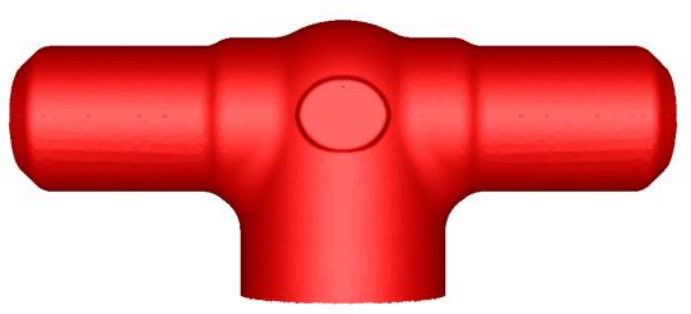

a) The forging from the simulation

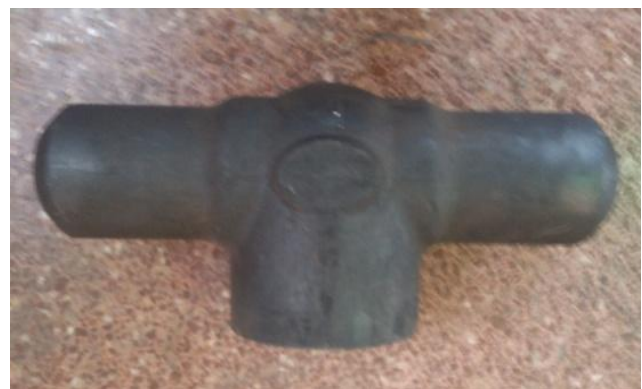

b) The forging from the experiment

Fig. 5 Comparison between the simulation and the experiment 


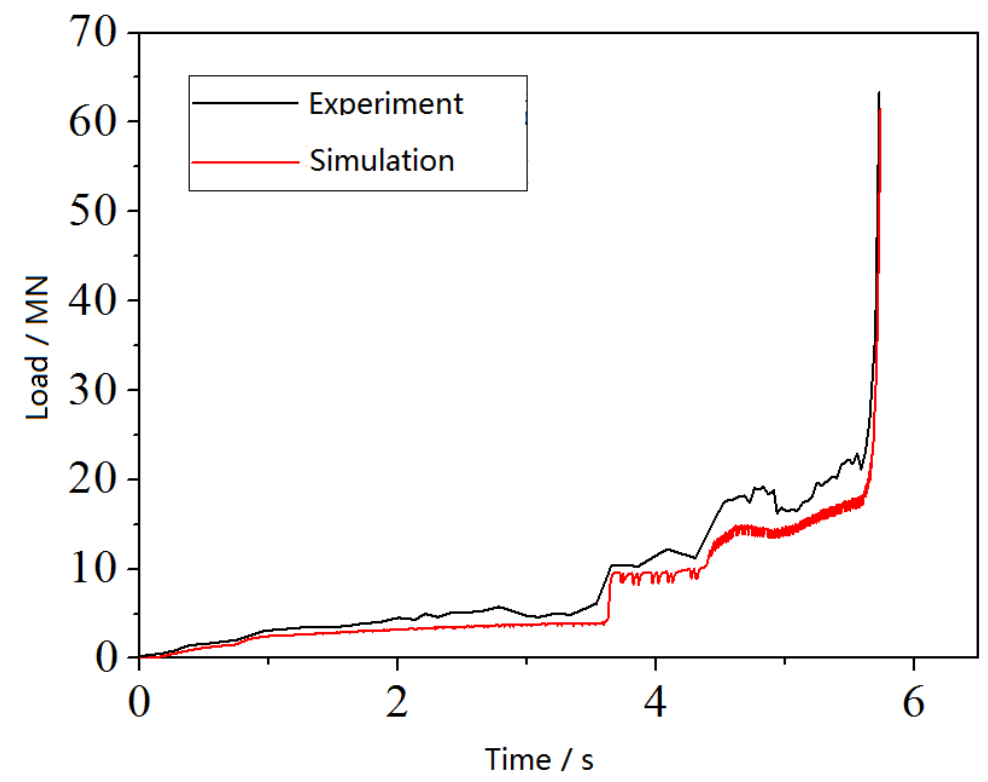

Fig. 6 Stroke vs. load curves from the simulation and the experiment

\section{Summary}

The numerical simulation of the multidirectional forging for a tee joint valve was carried out. The final temperature field shows that varying temperatures are within the feasible forging temperature region. The shape of the forging from the simulation is almost the same as that from the experiment. The predicted load value can be taken as reference to select the forming facility.

\section{Acknowledgement}

This research was financially supported by Shanghai University Knowledge Service Platform Project of Shanghai Municipal Education Commission, Project Number: ZF1225 as well as National Science and Technology Major Project, Project Number : 2012ZX04010082.

\section{References}

[1] C. Huang. The mould structure and design of the multidirectional forging. Metal of Forming Technology. 06 (2000) 06:28-29.

[2] L.J. Bai, Z. Zhang. The metal flow research of a square tee during multidirectional loadings. Thermal Processing Technology. 05 (2008) 64-66.

[3] Q. Li, K. M. Xue, M. L. Yuan. Thermal mechanical numerical simulation of a large-scale tee valve during the multidirectional forging process. The Mechanical Engineering Annual Meeting Proceedings of The Annual Meeting of the Science Association of Anhui Province. (2008) 05

[4] S. Shi, S. L. Ding, Q. Y. Zhu. Multidirectional forging research of a tee joint based on FEM. Thermal Processing Technology. 23 (2011) 109-111.

[5] J. M. Yu, M. Z. Zhang. Structural optimization design of a new active multidirectional loading mould. J. Mech. Eng.12 (2012) 43-48. 